\title{
The association between Chiari malformation Type I, spinal syrinx, and scoliosis
}

\author{
Jennifer Strahle, MD, ${ }^{1}$ Brandon W. Smith, MD, MS, ${ }^{1}$ Melaine Martinez, MD, ${ }^{1}$ \\ J. Rajiv Bapuraj, MBBS, MD, ${ }^{2}$ Karin M. Muraszko, MD, ${ }^{1}$ Hugh J. L. Garton, MD, MHSc, ${ }^{1}$ \\ and Cormac O. Maher, MD ${ }^{1}$
}

Departments of ${ }^{1}$ Neurosurgery and ${ }^{2}$ Radiology, University of Michigan, Ann Arbor, Michigan

\begin{abstract}
OBJECT Chiari malformation Type I (CM-I) is often found in patients with scoliosis. Most previous reports of CM-I and scoliosis have focused on patients with $\mathrm{CM}-\mathrm{I}$ and a spinal syrinx. The relationship between $\mathrm{CM}-\mathrm{I}$ and scoliosis in the absence of a syrinx has never been defined clearly. The authors sought to determine if there is an independent association between $\mathrm{CM}-\mathrm{I}$ and scoliosis when controlling for syrinx status.
\end{abstract}

METHODS The medical records of 14,118 consecutive patients aged $\leq 18$ years who underwent brain or cervical spine $\mathrm{MRI}$ at a single institution in an 11-year span were reviewed to identify patients with CM-I, scoliosis, and/or syrinx. The relationship between $\mathrm{CM}-\mathrm{I}$ and scoliosis was analyzed by using multivariate regression analysis and controlling for age, sex, CM-I status, and syrinx status.

RESULTS In this cohort, 509 patients had CM-I, 1740 patients had scoliosis, and 243 patients had a spinal syrinx. The presence of CM-I, the presence of syrinx, older age, and female sex were each significantly associated with scoliosis in the univariate analysis. In the multivariate regression analysis, older age (OR 1.02 [95\% $\mathrm{Cl} 1.01-1.03]$; $p<0.0001)$, female sex (OR 1.71 [95\% Cl 1.54-1.90]; $p<0.0001$ ), and syrinx (OR 9.08 [95\% Cl 6.82-12.10]; $p<0.0001$ ) were each independently associated with scoliosis. CM-I was not independently associated with scoliosis when controlling for these other variables (OR 0.99 [95\% $\mathrm{Cl} 0.79-1.29] ; p=0.9$ ).

CONCLUSIONS A syrinx was independently associated with scoliosis in a large pediatric population undergoing MRI. $\mathrm{CM}$-I was not independently associated with scoliosis when controlling for age, sex, and syrinx status. Because CM-I is not independently associated with scoliosis, scoliosis should not necessarily be considered a symptom of low cerebellar tonsil position in patients without a syrinx.

http://thejns.org/doi/abs/10.3171/2014.11.PEDS14135

KEY WORDS Chiari malformation Type I; scoliosis; spinal syrinx

$\mathrm{C}$ HIARI malformation Type I (CM-I) is often associated with a spinal syrinx..$^{26,33}$ Patients who have both CM-I and a syrinx are more likely to undergo surgery than those with CM-I alone. ${ }^{28}$ For this reason, surgical series tend to overestimate the true prevalence of syrinxes associated with CM-I. ${ }^{24,33}$ When all patients with CM-I discovered on imaging are considered without selecting for those who are symptomatic or undergoing treatment, a syrinx is found in a smaller, but still substantial, percentage of those with CM-I. ${ }^{30}$ Spinal syrinx is associated with scoliosis in some individuals, $3,18,19,36$ perhaps as a result of asymmetrical injury to the spinal cord from an expanding cyst. ${ }^{16}$
Although most researchers agree that CM-I can cause a spinal syrinx and that a spinal syrinx can cause scoliosis, $3,5,6,11,12,15,20$ the association of CM-I and scoliosis in the absence of a syrinx has never been defined properly and remains controversial. Some researchers have speculated that asymmetrical compression of the cervicomedullary junction by the cerebellar tonsils can result in scoliosis even in the absence of a spinal syrinx..$^{5,6,34,37}$ Nevertheless, there is scant existing evidence for such a causal relationship between CM-I and scoliosis in the absence of a syrinx. Arguing in favor of such a relationship are several case reports of patients with CM-I and scoliosis in the absence of a syrinx.$^{13,22,34}$ However, given the high preva- 
lence of both $\mathrm{CM}-\mathrm{I}^{23,30}$ and scoliosis, ${ }^{7,35}$ both conditions in an individual can occur by chance in many instances. Therefore, the existence of reports of individual patients or even small series of patients with both findings does not prove a causative relationship. In addition, there are case series in which CM-I as a cause of scoliosis has been examined..$^{11,20,34}$ Unfortunately, a majority of these patients also have a spinal syrinx, making it impossible to draw any conclusion on the relationship between CM-I and scoliosis in the absence of a syrinx. To examine this relationship, we analyzed a large cohort of children who, over an 11-year span, underwent brain or cervical spine MRI. We then performed multivariate regression analysis to determine if there was an independent relationship between $\mathrm{CM}-\mathrm{I}$ and scoliosis when we controlled for syrinx status.

\section{Methods}

After approval by the University of Michigan Institutional Review Board, we examined the medical records of 14,118 consecutive children aged $\leq 18$ years who underwent brain or cervical spine MRI at the University of Michigan in an 11-year span. Electronic records, including radiology reports, surgical reports, all office consultation notes, and hospital chart entries, were reviewed by using the Electronic Medical Record Search Engine (EMERSE) ${ }^{14}$ to identify patients with CM-I, syrinx, and/ or scoliosis by searching for the key words "tonsillar ectopia," "tonsillar herniation," "tonsillar descent," "tonsil," "syrinx," "syringomyelia," "hydromyelia," "Chiari," or "scoliosis" in any part of the electronic medical record. All imaging records and all other medical records for patients selected in this way were reviewed to confirm the diagnoses.

Each patient was assigned to a category on the basis of his or her syrinx status, CM-I status, and scoliosis status. For the purpose of this analysis, CM-I was defined on imaging as a cerebellar tonsil position at least $5 \mathrm{~mm}$ below the foramen magnum. ${ }^{1,4,29,30}$ A spinal syrinx was defined as a spinal cord cyst (hypointense signal on T1-weighted images and hyperintense signal on T2-weighted images) of at least $3 \mathrm{~mm}$ wide seen on an axial image. ${ }^{30}$ Scoliosis was defined as at least a $10^{\circ} \mathrm{Cobb}$ angle seen on a radiograph. Although radiographs were available for most of the patients with a diagnosis of scoliosis, those without radiographs but with a clear description and diagnosis of scoliosis in the medical record were also included in the scoliosis category.

There were 554 patients excluded from analysis. Patients were excluded if they had Chiari malformation Type II or III or any risk factors for low cerebellar tonsil position other than idiopathic CM-I, including mass effect from tumor, hydrocephalus, intracranial cysts, cerebral edema, or craniosynostosis. Patients who received surgical treatment for CM-I before their first MRI at our institution were excluded. Patients with a syrinx and Chiari malformation Type 0 , intramedullary spinal cord tumor, or open myelomeningocele were also excluded. The final analysis included 13,564 patients.

Statistical significance calculations were obtained using the chi-square test, the t-test, ANOVA, and multivari- ate regression analysis. Multivariate regression analysis for scoliosis was performed while taking into account CM-I status, syrinx status, sex, and age. Raw odds ratios (ORs) were produced using $2 \times 2$ tables and chi-square testing. Data were analyzed using SAS 9.3 (SAS Institute, Inc.) and StatPlus (AnalystSoft, Inc.) software. For the multivariate regression analysis, we analyzed CM-I as a categorical variable rather than a continuous variable; patients with a cerebellar tonsil position of $\geq 5 \mathrm{~mm}$ below the foramen magnum were analyzed together. Scoliosis and syrinxes were also analyzed as categorical variables for multivariate regression analysis.

\section{Results}

In this cohort of 13,564 patients, $52 \%$ were male, and the mean age at the time of MRI was 7.7 years. Scoliosis was present in 1740 patients (12.8\%), 509 patients (3.8\%) had a cerebellar tonsil position of $\geq 5 \mathrm{~mm}$ below the foramen magnum, and $243(1.8 \%)$ had a syrinx of $\geq 3 \mathrm{~mm}$ in maximal diameter. Of the 1740 patients with scoliosis, 114 (6.6\%) had CM-I, 137 (7.9\%) had a syrinx, and 72 (4.1\%) had both CM-I and a syrinx.

Of the 114 patients with both CM-I and scoliosis, 72 had a syrinx and 42 did not (Table 1). The mean age at the time of the scoliosis diagnosis was 9.5 years (Fig. 1). There was no difference in the mean ages at diagnosis between those with and those without a syrinx. There was a similar sex distribution for those with a syrinx (69.4\% female) and those without a syrinx (69.0\% female). The patients with both CM-I and a syrinx had a lower cerebellar tonsil position (mean $12.9 \mathrm{~mm}$ ) than those with CM-I and no syrinx (mean $9.1 \mathrm{~mm}$; $\mathrm{p}<0.001$ ). Patients with a syrinx were more likely to have a curve of $>20^{\circ}(70.8 \%)$ than those without a syrinx $(45.2 \% ; \mathrm{p}<0.01)$. The locations of the curve with the largest Cobb angle for the group as a whole were distributed similarly between the thoracic $(51 \%)$ and thoracolumbar $(46 \%)$ regions, with a minority in the lumbar spine (2.6\%). Thirteen patients $(11.4 \%)$ had a left thoracic curve. Neither the presence of a syrinx $(\mathrm{p}=$ $0.9)$ nor the syrinx width $(p=0.3)$ was related to the presence of a left thoracic curve. The average greatest curve was $31^{\circ}$. There was no association between cerebellar ton-

TABLE 1. Characteristics of the study patients with CM-I and scoliosis $(n=114)$

\begin{tabular}{lccc}
\hline \multicolumn{1}{c}{ Characteristic } & $\begin{array}{c}\text { Syrinx } \\
(\mathrm{n}=72)\end{array}$ & $\begin{array}{c}\text { No Syrinx } \\
(\mathrm{n}=42)\end{array}$ & p Value \\
\hline Female (no. [\%]) & $50(69.4)$ & $29(69.0)$ & 0.96 \\
\hline $\begin{array}{l}\text { Mean age at scoliosis diagnosis } \\
\text { (yrs) }\end{array}$ & 9.4 & 9.7 & 0.3 \\
\hline Lt thoracic curve (no. [\%]) & $8(11.1)$ & $5(11.9)$ & 0.9 \\
\hline Degree of greatest curve $\left(^{\circ}\right)$ & 32.1 & 28.5 & 0.10 \\
\hline Patients w/ $\leq 20^{\circ}$ curve $($ no. $[\%])$ & $21(29.2)$ & $23(54.8)$ & $<0.01$ \\
\hline Patients w/ $>20^{\circ}$ curve (no. [\%]) & $51(70.8)$ & $19(45.2)$ & $<0.01$ \\
\hline $\begin{array}{c}\text { Mean cerebellar tonsil position } \\
(\text { mm })^{*}\end{array}$ & 12.9 & 9.1 & $<0.001$ \\
\hline$*$ Below the foramen magnum. & & \\
\hline
\end{tabular}

* Below the foramen magnum. 


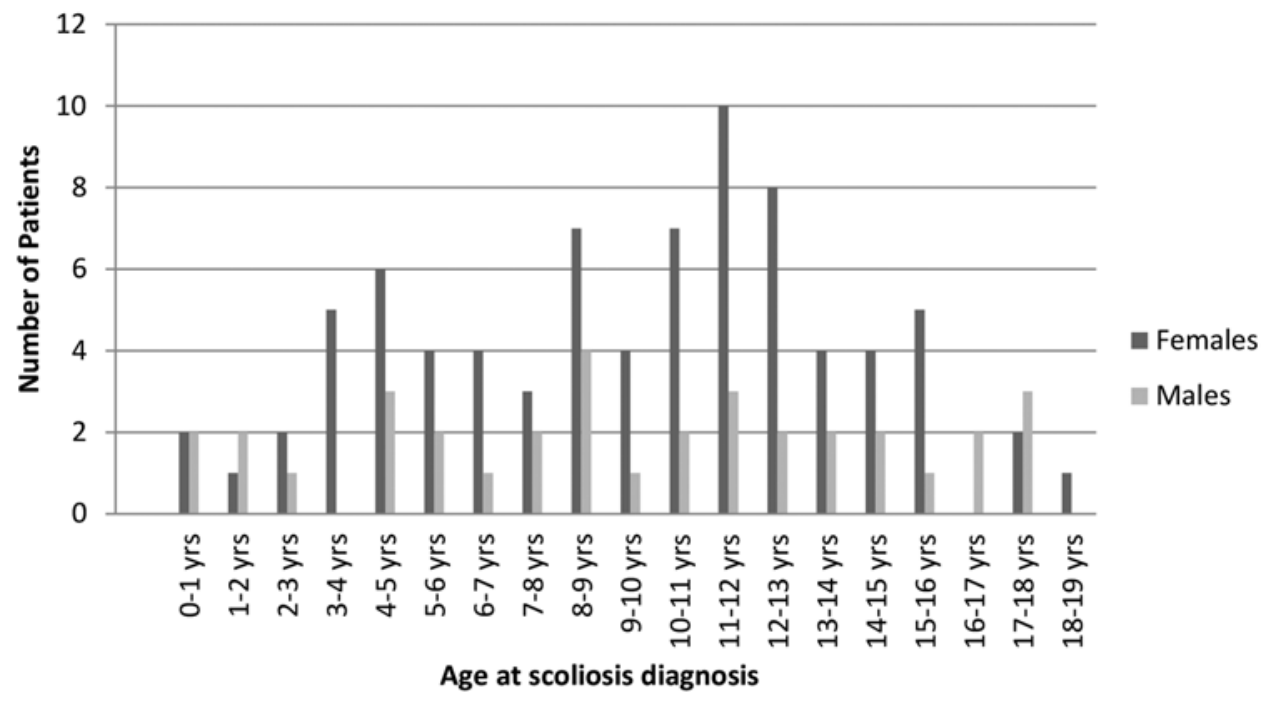

FIG. 1. Bar graph illustrating the number of patients with $\mathrm{CM}-\mathrm{I}$ stratified according to age at the time of their scoliosis diagnosis.

sil position (analyzed as a continuous variable; $p=0.7$ ) or cerebrospinal fluid flow (categorized as normal, decreased anterior/posterior to the foramen magnum, or abnormal tonsillar pulsations) at the foramen magnum $(\mathrm{p}=0.7)$ and the degree of the largest curve. There were no associations between syrinx width (analyzed as a continuous variable; $\mathrm{p}=0.4)$ or cranial extent of the syrinx $(\mathrm{p}=0.8)$ and the degree of the greatest curve. There were no differences in sex, age at CM-I diagnosis, cerebellar tonsil position, or cerebrospinal fluid flow in patients who presented with a curve of $>20^{\circ}$ versus those who presented with a curve of $\leq 20^{\circ}$.

In univariate analysis of the risk factors for scoliosis in the 13,564 patients who underwent MRI, female sex ( $\mathrm{p}<$ $0.0001)$, presence of a syrinx ( $\mathrm{p}<0.0001)$, and presence of CM-I ( $p<0.0001)$ were each significantly associated with scoliosis. In multivariate regression analysis, female sex ( $p$ $<0.0001)$, older age ( $<0.0001)$, and presence of a syrinx $(\mathrm{p}<0.0001)$ were independently associated with scoliosis. CM-I was not independently associated with scoliosis when we controlled for these other factors $(p=0.9)$. ORs were calculated for these variables after performing the univariate and multivariate analyses (Table 2). ORs were calculated for female sex (OR 1.71 [95\% CI 1.54-1.90]), older age (OR 1.02 [95\% CI 1.01-1.03]), and syrinx (OR 9.08 [95\% CI 6.82-12.10]) in multivariate analysis. CM-I was not independently associated with scoliosis when we controlled for these other variables (OR 0.99 [95\% CI $0.79-1.29])$.

\section{Discussion}

Patients with both CM-I and scoliosis are frequently referred to neurosurgeons for consideration of Chiari decompression surgery. When a syrinx is also present, the decision to proceed with Chiari decompression is not controversial, ${ }^{28}$ because the association between CM-I and syrinxes is well established. ${ }^{10,26}$ It is also clear that those patients with both CM-I and a syrinx are at risk for scoliosis. ${ }^{11,30,32}$ Our data confirmed this well-established association between syrinxes and scoliosis. The management of a patient with scoliosis and an otherwise asymptomatic CM-I is not as clear in the absence of an associated syrinx. Our goal was to evaluate this relationship in the absence of a syrinx by analyzing the independent association between CM-I and scoliosis while controlling for syrinx status. ORs from the multivariate analysis indicate that syrinxes, female sex, and age have associations with scoliosis. Because the OR for older age was close to 1 , we believe that this finding is unlikely to be clinically significant. Most important is that CM-I was not independently associated with scoliosis in our multivariate analysis.

Some reports have suggested that there is an independent relationship between low cerebellar tonsil position and scoliosis, $, 2,8,9,18,25,31$ perhaps as a result of dorsal compression of the cervicomedullary junction by the tonsils. ${ }^{5,6,37}$ However, much of the existing evidence that could be used to suggest an independent association for CM-I and scoliosis in the absence of a syrinx is inconclusive. First, there have been several reports of patients with CM-I and sco-

TABLE 2. Odds ratios for scoliosis in the study cohort

\begin{tabular}{|c|c|c|c|c|}
\hline \multirow[b]{2}{*}{ Characteristic } & \multicolumn{2}{|c|}{ Univariate Analysis } & \multicolumn{2}{|c|}{ Multivariate Analysis } \\
\hline & $p$ Value & OR $(95 \% \mathrm{Cl})$ & $p$ Value & OR $(95 \% \mathrm{Cl})$ \\
\hline Female sex & $<0.0001$ & $1.76(1.59-1.95)$ & $<0.0001$ & $1.71(1.54-1.90)$ \\
\hline Syrinx & $<0.0001$ & $9.45(7.29-12.24)$ & $<0.0001$ & $9.08(6.82-12.10)$ \\
\hline CM-I & $<0.0001$ & $2.03(1.64-2.51)$ & 0.94 & $0.99(0.79-1.29)$ \\
\hline
\end{tabular}


liosis without syringomyelia; however, most of these cases were drawn from larger case series that included a majority of patients with a syrinx and CM-I. ${ }^{12,13,22,34}$ Because both low cerebellar tonsil position and scoliosis are common, it is not surprising that many individuals with both conditions have been identified. $7,23,30,35$ Others have cited an improvement in scoliosis after CM-I decompression in patients without an associated syrinx; $;^{12,17,34}$ however, most patients in these series had a syrinx, making it difficult to support any independent effect of CM-I without a syrinx. ${ }^{17}$ Also, the natural history of scoliosis is variable, so it is not clear whether a few examples of postsurgical improvement in patients without a syrinx differs from the natural history of this condition seen in other individuals. ${ }^{34}$ Minor curve improvements are not unusual within groups of patients with scoliosis followed without treatment, ${ }^{21}$ and on the basis of the existing literature, it is difficult to make a case for the therapeutic benefit of Chiari decompression surgery to treat scoliosis in the absence of a syrinx.

Other evidence that has been cited to support the notion that CM-I may cause scoliosis in the absence of a syrinx is the prevalence of CM-I on screening MR images of patients undergoing scoliosis repair. ${ }^{18,25}$ Several studies have noted an association of low cerebellar tonsil position and idiopathic scoliosis. $2,8,9,18,25,31$ Cerebellar tonsil position, however, is distributed in an approximately normal distribution pattern across all age groups, and low tonsil position is not rare, even in healthy individuals..$^{29}$ Furthermore, some groups have used definitions for tonsil ectopia in patients with scoliosis that fall within the range of normal tonsil position as it is usually defined. ${ }^{8,27,31}$ These reports confirm only that CM-I is found in a small percentage of patients with scoliosis, not that there is an independent association between CM-I and scoliosis. It is notable as well that these studies found no association between low tonsil position and the severity of curve or the presence of an atypical curve.,, 31

We analyzed a large number of patients in an MRI database to study the relationship between CM-I and syrinxes. Patients in this cohort were categorized by CM-I, syrinx, and scoliosis status. When we controlled for known risk factors for scoliosis, including presence of a syrinx, female sex, and age, there was no longer an independent association between CM-I and scoliosis. When CM-I is associated with a syrinx, there is an increased risk for scoliosis and, on the basis of our analysis, this increased risk is most likely from the syrinx. In cases of CM-I without a syrinx, no association with scoliosis was found. We conclude that although CM-I is associated with syrinxes and syrinxes are associated with scoliosis, the syrinx is a necessary intermediary in most cases. When CM-I is present without a syrinx, there does not seem to be a significantly increased risk of scoliosis.

There are several limitations to our study. The patients we analyzed are representative of those who underwent MRI at a tertiary referral center and therefore do not represent a true population cohort. The cohort of patients in the study was derived from all individuals who underwent brain or cervical spine imaging in an 11-year span, which ensured that cerebellar tonsil position could be assessed accurately in every case. Because patients with scoliosis are more likely to be referred for diagnostic imaging, there was a detection bias for scoliosis in this study. For this reason, the number of detected cases of scoliosis in this group was higher than would be expected in the population as a whole. The original imaging interpretation was performed by unblinded observers and, therefore, was subject to observer bias. Finally, the multivariate regression included CM-I status, presence of a syrinx, sex, and age but did not include other potentially important factors such as a history of meningitis, subarachnoid hemorrhage, or bony abnormalities.

We did not find an independent association between CM-I and scoliosis after controlling for syrinx status. The lack of an independent association indicates that CM-I is unlikely to be causative for scoliosis in the absence of a spinal syrinx. Finally, and most important, the lack of an independent association casts some doubt on the existence of any putative therapeutic benefit of CM-I decompression surgery for treating scoliosis alone in the absence of a syrinx or other symptoms.

\section{Conclusions}

There is a strong association between syrinxes and scoliosis, but there does not seem to be a significant relationship between CM-I and scoliosis when controlling for the presence of a syrinx.

\section{Acknowledgment}

We thank Holly Wagner for providing editorial assistance.

\section{References}

1. Aboulezz AO, Sartor K, Geyer CA, Gado MH: Position of cerebellar tonsils in the normal population and in patients with Chiari malformation: a quantitative approach with MR imaging. J Comput Assist Tomogr 9:1033-1036, 1985

2. Abul-Kasim K, Overgaard A, Karlsson MK, Ohlin A: Tonsillar ectopia in idiopathic scoliosis: does it play a role in the pathogenesis and prognosis or is it only an incidental finding? Scoliosis 4:25, 2009

3. Akhtar OH, Rowe DE: Syringomyelia-associated scoliosis with and without the Chiari I malformation. J Am Acad Orthop Surg 16:407-417, 2008

4. Barkovich AJ, Wippold FJ, Sherman JL, Citrin CM: Significance of cerebellar tonsillar position on MR. AJNR Am J Neuroradiol 7:795-799, 1986

5. Brockmeyer D, Gollogly S, Smith JT: Scoliosis associated with Chiari 1 malformations: the effect of suboccipital decompression on scoliosis curve progression: a preliminary study. Spine (Phila Pa 1976) 28:2505-2509, 2003

6. Brockmeyer DL: Editorial. Chiari malformation Type I and scoliosis: the complexity of curves. J Neurosurg Pediatr 7:22-24, 2011

7. Campos MA, Weinstein SL: Pediatric scoliosis and kyphosis. Neurosurg Clin N Am 18:515-529, 2007

8. Cheng JC, Chau WW, Guo X, Chan YL: Redefining the magnetic resonance imaging reference level for the cerebellar tonsil: a study of 170 adolescents with normal versus idiopathic scoliosis. Spine (Phila Pa 1976) 28:815-818, 2003

9. Cheng JC, Guo X, Sher AH, Chan YL, Metreweli C: Correlation between curve severity, somatosensory evoked potentials, and magnetic resonance imaging in adolescent idiopathic scoliosis. Spine (Phila Pa 1976) 24:1679-1684, 1999 
10. Dauser RC, DiPietro MA, Venes JL: Symptomatic Chiari I malformation in childhood: a report of 7 cases. Pediatr Neurosci 14:184-190, 1988

11. Eule JM, Erickson MA, O’Brien MF, Handler M: Chiari I malformation associated with syringomyelia and scoliosis: a twenty-year review of surgical and nonsurgical treatment in a pediatric population. Spine (Phila Pa 1976) 27:1451-1455, 2002

12. Farley FA, Puryear A, Hall JM, Muraszko K: Curve progression in scoliosis associated with Chiari I malformation following suboccipital decompression. J Spinal Disord Tech 15:410-414, 2002

13. Flynn JM, Sodha S, Lou JE, Adams SB Jr, Whitfield B, Ecker ML, et al: Predictors of progression of scoliosis after decompression of an Arnold Chiari I malformation. Spine (Phila Pa 1976) 29:286-292, 2004

14. Hanauer DA: EMERSE: The Electronic Medical Record Search Engine. AMIA Annu Symp Proc 941:941, 2006

15. Hankinson TC, Klimo P Jr, Feldstein NA, Anderson RC, Brockmeyer D: Chiari malformations, syringohydromyelia and scoliosis. Neurosurg Clin N Am 18:549-568, 2007

16. Huebert HT, MacKinnon WB: Syringomyelia and scoliosis. J Bone Joint Surg Br 51:338-343, 1969

17. Hwang SW, Samdani AF, Jea A, Raval A, Gaughan JP, Betz RR, et al: Outcomes of Chiari I-associated scoliosis after intervention: a meta-analysis of the pediatric literature. Childs Nerv Syst 28:1213-1219, 2012

18. Inoue M, Minami S, Nakata Y, Otsuka Y, Takaso M, Kitahara H, et al: Preoperative MRI analysis of patients with idiopathic scoliosis: a prospective study. Spine (Phila Pa 1976) 30:108-114, 2005

19. Joseph RN, Batty R, Raghavan A, Sinha S, Griffiths PD, Connolly DJ: Management of isolated syringomyelia in the paediatric population-a review of imaging and follow-up in a single centre. Br J Neurosurg 27:683-686, 2013

20. Krieger MD, Falkinstein Y, Bowen IE, Tolo VT, McComb JG: Scoliosis and Chiari malformation Type I in children. J Neurosurg Pediatr 7:25-29, 2011

21. Lloyd-Roberts GC, Pincott JR, McMeniman P, Bayley IJ, Kendall B: Progression in idiopathic scoliosis: a preliminary report of a possible mechanism. J Bone Joint Surg Br 60B: $451-460,1978$

22. Loder RT, Stasikelis P, Farley FA: Sagittal profiles of the spine in scoliosis associated with an Arnold-Chiari malformation with or without syringomyelia. J Pediatr Orthop 22:483-491, 2002

23. Meadows J, Kraut M, Guarnieri M, Haroun RI, Carson BS: Asymptomatic Chiari Type I malformations identified on magnetic resonance imaging. J Neurosurg 92:920-926, 2000

24. Milhorat TH, Chou MW, Trinidad EM, Kula RW, Mandell M, Wolpert C, et al: Chiari I malformation redefined: clinical and radiographic findings for 364 symptomatic patients. Neurosurgery 44:1005-1017, 1999

25. Nakahara D, Yonezawa I, Kobanawa K, Sakoda J, Nojiri H, Kamano S, et al: Magnetic resonance imaging evaluation of patients with idiopathic scoliosis: a prospective study of four hundred seventy-two outpatients. Spine (Phila Pa 1976) 36:E482-E485, 2011

26. Oldfield EH, Muraszko K, Shawker TH, Patronas NJ: Pathophysiology of syringomyelia associated with Chiari I malformation of the cerebellar tonsils. Implications for diagnosis and treatment. J Neurosurg 80:3-15, 1994

27. Proctor M, Scott RM: Redefining the magnetic resonance imaging reference level for the cerebellar tonsil: a study of 170 adolescents with normal versus idiopathic scoliosis. Spine (Phila Pa 1976) 29:105-106, 2004 (Letter)

28. Rocque BG, George TM, Kestle J, Iskandar BJ: Treatment practices for Chiari malformation type I with syringomyelia: results of a survey of the American Society of Pediatric Neurosurgeons. J Neurosurg Pediatr 8:430-437, 2011

29. Smith BW, Strahle J, Bapuraj JR, Muraszko KM, Garton HJ, Maher CO: Distribution of cerebellar tonsil position: implications for understanding Chiari malformation. J Neurosurg 119:812-819, 2013

30. Strahle J, Muraszko KM, Kapurch J, Bapuraj JR, Garton HJ, Maher CO: Chiari malformation Type I and syrinx in children undergoing magnetic resonance imaging. J Neurosurg Pediatr 8:205-213, 2011

31. Sun X, Qiu Y, Zhu Z, Zhu F, Wang B, Yu Y, et al: Variations of the position of the cerebellar tonsil in idiopathic scoliotic adolescents with a Cobb angle $>40$ degrees: a magnetic resonance imaging study. Spine (Phila Pa 1976) 32:1680-1686, 2007

32. Tokunaga M, Minami S, Isobe K, Moriya H, Kitahara H, Nakata Y: Natural history of scoliosis in children with syringomyelia. J Bone Joint Surg Br 83:371-376, 2001

33. Tubbs RS, Beckman J, Naftel RP, Chern JJ, Wellons JC III, Rozzelle CJ, et al: Institutional experience with 500 cases of surgically treated pediatric Chiari malformation Type I. J Neurosurg Pediatr 7:248-256, 2011

34. Tubbs RS, Doyle S, Conklin M, Oakes WJ: Scoliosis in a child with Chiari I malformation and the absence of syringomyelia: case report and a review of the literature. Childs Nerv Syst 22:1351-1354, 2006

35. Weinstein SL, Dolan LA, Cheng JC, Danielsson A, Morcuende JA: Adolescent idiopathic scoliosis. Lancet 371:1527-1537, 2008

36. Yeom JS, Lee CK, Park KW, Lee JH, Lee DH, Wang KC, et al: Scoliosis associated with syringomyelia: analysis of MRI and curve progression. Eur Spine J 16:1629-1635, 2007

37. Zhu Z, Wu T, Sha S, Sun X, Zhu F, Qian B, et al: Is curve direction correlated with the dominant side of tonsillar ectopia and side of syrinx deviation in patients with single thoracic scoliosis secondary to Chiari malformation and syringomyelia? Spine (Phila Pa 1976) 38:671-677, 2013

\section{Author Contributions}

Conception and design: Maher, Strahle. Acquisition of data: all authors. Analysis and interpretation of data: Maher, Strahle, Smith. Drafting the article: Maher, Strahle, Garton, Muraszko. Critically revising the article: Maher, Strahle. Reviewed submitted version of manuscript: all authors. Approved the final version of the manuscript on behalf of all authors: Maher. Study supervision: Maher.

\section{Correspondence}

Cormac O. Maher, Department of Neurosurgery, University of Michigan, 1500 E. Medical Center Dr., Rm. 3552 Taubman Center, Ann Arbor, MI 48109-5338. email: cmaher@umich.edu. 